Results 168 children included aged $5.1 \pm 0.1$ years. 133 pretermborn children, born: $29.2 \pm 1.4$ weeks gestation; 35 full-term children aged five.

Systolic BP (sBP) was $97.5 \pm 7.1 \mathrm{mmHg}$ in preterm-born children versus $92.2 \pm 8.1 \mathrm{mmHg}$ in full-term controls, $p=0.0001$. In pretermborn children, sBP increased by $(\beta \pm \sigma): 2.2 \pm 1.0 \mathrm{mmHg}$ for each $\mathrm{gram} / \mathrm{kg}$ increase in proteins/day on day 28 , and decreased by $-3.0 \pm 1.4$ in case of bronchopulmonary dysplasia, after adjustment on gender and height at five years.

eGFR was $176.3 \pm 37.1 \mathrm{~mL} / \mathrm{min} / 1.73 \mathrm{~m}^{2}$ at five in preterm-born children. It was significantly decreased when children had presented hyaline membrane disease or necrotising enterocolitis, respectively $(\beta \pm \sigma):-17.6 \pm 6.7$ and $-25.7 \pm 10.4 \mathrm{~mL} / \mathrm{min} / 1.73 \mathrm{~m}^{2}$. eGFR at five was not associated with neonatal nutrition.

$14.4 \%$ preterm-born children had an albumin ratio $>2 \mathrm{mg} / \mathrm{mmol}$ vs. $11.1 \%$ full-terms, $\mathrm{p}=0.7$.

Renal volume, absolute or relative, at five years was negatively correlated to protein intakes from day 14 onwards in the neonatal period: $R=-0.69, p=0.006$.

Conclusion Protein intakes in the neonatal period are associated to an increased BP and decreased renal volume in five year-old pretermborn children.

\section{HUMAN MILK FORTIFICATION WITH DIFFERENT AMOUNTS OF FORTIFIER AND ITS ASSOCIATION WITH GROWTH AND METABOLIC RESPONSES OF PRETERM INFANTS}

doi:10.1136/archdischild-2012-302724.1388

${ }^{1} \mathrm{HG}$ Kanmaz, ${ }^{2 B}$ Mutlu, ${ }^{2} \mathrm{FE}$ Canpolat, ${ }^{2} \mathrm{O}$ Erdeve, ${ }^{2} \mathrm{U}$ Dilmen. ${ }^{1}$ Neonatology Unit; ${ }^{2} Z e k a i$ Tahir Burak Maternity Teaching Hospital, Ankara, Turkey

Background Fortification of human milk (HM) is a common clinical practice to adapt human milk to the nutritional needs of very low birth weight infants. The optimal method for HM fortification still remains to be determined and a great variety of protocols are currently used in the neonatal intensive care units.

Objective Since it is believed that the standard fortification is insufficient to meet the needs of VLBW, we designed a randomized prospective study in which blind fortification was administered in three different amounts of fortifier and aimed to assess short term growth and metabolic responses of preterm infants.

Methods Eligible infants were randomized into three groups; standard fortification (SF), moderate fortification (MF) and aggressive fortification (AF) groups. Short term growth, feeding intolerance and urea, calcium, phosphorus, alkaline phosphatase levels were assessed.

Results Twenty six, 29 and 29 infants were eligible in SF, MF and AF group, respectively. The baseline characteristics of the groups were similar. Daily weight gain, length at discharge did not differ between groups however head circumference was significantly higher in MF and AF group when compared with SF group. Urea, calcium, phosphorus, alkaline phosphatase levels were similar between groups.

Conclusion We demonstrated that blind fortification of HM even with higher amounts than recommended by commercials was safe and did cause a marked effect on weekly increase in head circumference but not on the other anthropometric measurements and metabolic responses of preterm infants.

\section{PARENTERAL NUTRITION IN VERY LOW BIRTH WEIGHT NEWBORNS: AUDIT OF CLINICAL PRACTICE}

doi:10.1136/archdischild-2012-302724.1389

'A Madhavan, 'M Yadav. 'Manchester Medical School, University of Manchester, Manchester; '2Department of Neonatology, Royal Bolton Hospital NHS Foundation Trust, Bolton, UK
Background and Aims Parenteral nutrition (PN) is an integral part of neonatal intensive care, especially in the early nutritional support of very low birthweight (VLBW) newborns. However, it is associated with potentially serious complications such as sepsis and metabolic derangement. The aim of the study was to review PN use and complications in VLBW newborns at Royal Bolton Hospital with specific European Society of Paediatric Gastroenterology, Hepatology and Nutrition (ESPGHAN) guidelines as the standard.

Methods PN use was reviewed in all VLBW newborns who received PN for more than 1 day during January 2009 to December 2010. ESPGHAN standards audited were the time of commencement of PN and composition of the PN bag.

Results Of the 42 VLBW newborns included, the median gestational age and weight was $27^{+0}$ weeks and $923 \mathrm{~g}$ respectively. In this group, $24 \%$ of newborns met the ESPGHAN standard for amino acid commencement and $88 \%$ for lipid commencement. The glucose and phosphate content of the PN bag did not match ESPGHAN standards as the glucose content was higher and phosphate content lower than recommended. Most common PN complication was hyperglycaemia (64\%), followed by hypophosphataemia (45\%) and sepsis (38\%). Coagulase negative Staphylococci were the most common organism cultured ( $94 \%$ ).

Conclusion There was a delay in commencement of PN. To achieve full compliance with ESPGHAN guidelines, amino acids and lipids should be commenced as recommended. Modifying constituents of the PN bag may help reduce complication rates of hyperglycaemia and hypophosphataemia.

\section{BACTERIAL COLONIZATION OF PRETERM INFANTS: IMPACT OF BIOFILM FORMATION ON THE NASOGASTRIC FEEDING TUBES}

doi:10.1136/archdischild-2012-302724.1390

'M Gómez, 'L Moles, ${ }^{2} \mathrm{~A}$ Melgar, ${ }^{2} \mathrm{G}$ Bustos, ${ }^{1} \mathrm{JM}$ Rodríguez. ${ }^{1} D p t o$. Nutrición, Bromatología y Tecnología de los Alimentos, Universidad Complutense de Madrid; ${ }^{2}$ Hospital Materno Infantil 12 de Octubre de Madrid, Madrid, Spain

Background Nowadays, hospitals foment breastfeeding or human donor milk to provide the best feeding option to the preterm infant. This fact may represent a key factor in the initiation and development of the infant gut microbiota.

Aims To analyse the bacterial diversity in meconium and feces of preterm neonates and to evaluate the impact of the nasogastric enteral feeding tubes and the feeding option in its evolution.

Method 26 mother/preterm neonates ( $<32$ weeks gestation) pairs participated in the study providing a sample of colostrum/breast milk and meconium/feces. Milk samples were obtained after their pass through the nasogastric feeding tubes. Samples were plated onto different culture media. The isolates were identified by PCR sequencing. Scanning electron microscopy (SEM) was used to observe biofilm formation on the feeding tubes.

Results Approximately 4,000 isolates were identified. The dominant genera in both samples were Staphylococcus, Enterococcus, Serratia, Klebsiella and Escherichia. They were present at high concentrations independently of the feeding option. Lactobacilli and bifidobacteria were detected in a low percentage of the samples. Analysis of several parts of the nasogastric tubes by SEM revealed the presence of a dense bacterial biofilm. Biofilms were composed of the same bacterial groups that dominated in the fecal and milk/ formula samples.

Conclusions There is a direct relationship between the high bacterial concentrations found in the biological samples and the biofilm formed in the nasogastric tubes. Fecal microbiota of preterm neonates are strongly influenced by those species highly prevalent the hospitalary environment. 
1391 BLOOD UREA NITROGEN CONCENTRATION DURING EARLY AND AGGRESSIVE PARENTAL AMINO ACID ADMINISTRATION IN EXTREMELY LOW BIRTH WEIGHT INFANTS

doi:10.1136/archdischild-2012-302724.1391

${ }^{1} \mathrm{HJ}$ Lee, ${ }^{2} \mathrm{CW}$ Choi. ${ }^{1}$ Hanyang University College of Medicine, Seoul; ${ }^{2}$ pediatrics, Clinical Research Institute, Seoul National University Bundang Hospital, Seongnam, Republic of Korea

Background and Aims Early administration of parenteral amino acids (AA) has been shown to limit catabolism and improve growth in extremely low birth weight (ELBW) infants. This study aimed to evaluate an earlier, more aggressive administration of amino acids, was safe and well-tolerated, without clinically significant differences in metabolic acidosis or blood urea nitrogen (BUN).

Methods The 46 ventilator-dependent preterm infants less than $1000 \mathrm{~g}$ were retrospectively enrolled. The Early group received $\geq 3 \mathrm{~g} /$ $\mathrm{kg} / \mathrm{d}$ amino acids, while the Late group did not received a minimum of $\geq 3 \mathrm{~g} / \mathrm{kg} / \mathrm{d}$ parenteral $\mathrm{AA}$ at $\leq 3$ days of age.

Results An earlier, more aggressive administration of amino acids $(\geq 3 \mathrm{~g} / \mathrm{kg} / \mathrm{d}$ amino acids at $\leq 3$ days of age), was safe and welltolerated, without clinically significant differences in metabolic acidosis or BUN. There is no correlation between amino acid intake and BUN in ELBW infants within 7 days of life, Using multiple regression analysis, gestational age showed a significant negative correlation with BUN concentrations in ELBW infants within 7 days of life.

Conclusions High BUN in the early postnatal period might be related not only to amino acid oxidation and the infant's immaturity but also additional combined factors other than amino acid intolerance. Future studies are required to determine whether early and aggressive administration of amino acids is enough for optimal growth and neurodevelopmental outcome of ELBW infants.

\section{DOES ENTERAL PROTEIN INTAKE AFFECT RENAL GLOMERULAR AND TUBULAR FUNCTIONS IN VERY LOW BIRTH WEIGHT INFANTS?}

doi:10.1136/archdischild-2012-302724.1392

HG Kanmaz, B Mutlu, 0 Erdeve, FE Canpolat, SS Oguz, N Uras, U Dilmen; Zekai Tahir Burak Maternity Teaching Hospital, Ankara, Turkey

objectives and aim: Very low birth weight infants require 3-4 g/ $\mathrm{kg} /$ day protein intake to provide satisfactory postnatal growth rates and neurodevelopmental outcomes however they have fewer functional nephrons thereby, increasing vulnerability to impaired renal functions. The aim of this study was to investigate the effect of different amounts of enteral protein intake during the fortification of human milk on renal glomerular and tubular functions.

Material and Methods Preterm infants were randomized into three groups regarding their daily protein intakes as standard fortification $(3 \mathrm{~g} / \mathrm{kg} / \mathrm{d})$, moderate fortification $(3.3 \mathrm{~g} / \mathrm{kg} / \mathrm{d})$ and aggressive fortification $(3.6 \mathrm{~g} / \mathrm{kg} / \mathrm{d})$ groups. Serum urea, creatinin $(\mathrm{Cr})$, Cystatin $C$ (Cys-C) and urinary $\beta 2$ microglobulin $(\beta 2 \mathrm{M})$ levels were assessed and compared between groups.

Results Serum urea, Cr, Cys- $C$ and urinary $\beta 2 \mathrm{M}$ levels were similar in all three groups both on discharge and postnatal day 14 $(p>0.05)$. Mean $\mathrm{Cr}$ and $\beta 2 \mathrm{M}$ levels were significantly lower on discharge $(p<0.05)$ while Cys-C levels did not differ in time $(\mathrm{p}>0.05)$

Conclusion Enteral protein intake up to $3.6 \mathrm{~g} / \mathrm{kg} / \mathrm{d}$ did not altered the tubular and glomerular functions in very preterm infants. However, the long term renal effects in these infants maintained on a high protein intake remain unknown and should be addressed in future studies.

\section{REGIONAL STUDY FOR PREDICTIVE FACTORS OF BREASTFEEDING PRETERM INFANTS LESS THAN 33 WEEKS}

doi:10.1136/archdischild-2012-302724.1393

${ }^{1} \mathrm{C}$ Lucas, ${ }^{2} \mathrm{H}$ Gonny, ${ }^{3,4} \mathrm{C}$ Tripon, ' $\mathrm{K}$ Husseini, 'D Lapeyre, ${ }^{1} \mathrm{~F}$ Hay-Findler, ${ }^{1} \mathrm{~S}$ Robert. ${ }^{1}$ Pediatric Intensive Care Unit; ${ }^{2}$ Obstetrics; ${ }^{3}$ Neonatology, University Hospital of Poitiers, Poitiers; " ${ }^{2}$ Department of Neonatology, General Hospital of Angoulême, Angoulême, France

Objective To determine regional prevalence of breastfeeding very premature infants and identify factors influencing it's initiation at birth and continuation at discharge.

Study Design It was a prospective observational study in preterm $<33$ weeks of gestational age (GA) from January to December 2010 in Poitou-Charentes. Data were collected from infant report and using a questionnaire sent at home. The variables were analyzed with the $\mathrm{Chi}^{2}$ test and Student's $t$ test at $\mathrm{p}<0.05$ and binary logistic regression for predictive factors.

Results Questionnaires collected concerns 112/150 infants (74.7\%) and 95 parents (17 multiple pregnancy). At birth, 65.2\% $(n=73)$ were breastfed. Factors significantly associated with breastfeeding at birth were: maternal body mass index (BMI), employed mothers, mothers that have been breastfed (MoBr) and daycare other than grandparents. In a multivariate regression model, BMI, daycare by grandparents and $\mathrm{MoBr}$ were independent predictive factors of breastfeeding at birth with OR [IC 95\%]: 1.18 [1.011.38], 0.24 [0.08-0.74] and 5.8 [1.49-22.56] respectively. At discharge, $46.4 \%(n=52)$ of infants were breastfed. Factors significantly associated with breastfeeding at discharge were: intrapartum information about breastfeeding employed mothers, non smoker mothers, low paternal BMI, high educational level of fathers, daycare by grandparents, and $\mathrm{MoBr}$. The last 4 factors were independent predictors of breastfeeding at discharge in a multivariate binary logistic model with OR [IC 95\%]: 0.75 [0.62-0.9], 5.35 [1.24-23.1], 0.18 [0.03-0.96] and 7.5 [1.35-41.8] respectively.

Conclusion Socio-economic, educational and family conditions influence differently breastfeeding initiation and continuation. This diagnosis is precious to breastfeeding promotion programs.

\section{WEIGHT GAIN IN BABIES OF 28-32 WEEKS GESTATIONAL AGE; IMPACT OF A STANDARDISED ENTERAL FEEDING REGIME}

doi:10.1136/archdischild-2012-302724.1394

D Metheniti, A Papandreou, CS Narayanan. Neonatal Intensive Care Unit, West Hertfordshire Hospitals NHS Trust, Watford, UK

Background and Aims Earlier studies have shown that optimal early neonatal growth improves neurodevelopmental outcomes in preterm infants. A standardised enteral feeding regime (SEFR) was introduced across a UK neonatal network in April 2011. Effects of this standardisation on early neonatal growth are examined in our observational study.

Methods We retrospectively compared two cohorts of babies born in our unit at 28-31+6 weeks gestation during two epochs, one before and one after implementation of SEFR. Epoch1 extended between April and December 2010, Epoch2 between April and December 2011. Patients who were transferred in or out of the unit for continuation of care were excluded.

Results 20 patients were included in Epoch1(E1), 16 in Epoch2(E2). Baseline characteristics (gestation, birth weight, neonatal care) were similar between groups. E1 cohort regained birth weight in 11.65(6-17) days, reaching full enteral feeds at 7.3(2-18) days. E2 cohort regained birth weight in 11.06(5-18) days and reached full feeds at 7.88(5-15) days. TPN was used in $65 \%(n=13 / 20)$ of E1 cohort for $6.7(1-12)$ days and in $87.5 \%(n=14 / 16)$ of E2 cohort for 